Session 2793

\title{
Merging Data from Multiple Sources to Assess Performance Against Objectives
}

\author{
Dr. R. H. King \\ Engineering Division, Colorado School of Mines
}

1 Introduction

\subsection{Colorado School of Mines and the Engineering Division}

Since our paper describes methods of assessing performance against educational objectives, it is necessary to establish the institutional and program backgrounds for the objectives. The Colorado School of Mines (CSM) is a public research university devoted to engineering and applied science that has distinguished itself by developing high-quality graduates and scholarship. The U.S. News and World Report Inc. rated CSM 26th in the Top National Public Universities and 50th in the Best Undergraduate Engineering Programs with Ph.D. Programs in $2001^{1}$. The school's role as written in the Colorado statutes focuses on "energy, minerals, and materials science and engineering and science fields." The sequence of multidisciplinary laboratory courses described herein lies within the engineering focus and is taught within the Engineering Division.

The Engineering Division is the largest program at CSM with approximately 850 undergraduate majors and 70 graduate students. This population represents a shift from CSM's historical earth science and engineering focus. The undergraduate program is an ABET accredited, non-

traditional, interdisciplinary, Bachelor of Science Degree in Engineering with specialties in civil, electrical, environmental, and mechanical engineering, as well as graduate degrees (M. S., M. E. and $\mathrm{Ph}$. D) and research in engineering systems. The Gourman Report ranks the CSM Engineering Division fifth among general engineering programs ${ }^{2}$. Primary goals of the program are to provide students with a solid foundation in engineering fundamentals, the skills to adapt to rapidly changing and advanced technologies, and an aptitude for life-long learning. Uniqueness of the program is particularly evident with respect to its multidisciplinary span, heavy experimental component, large credit-hour requirement, and use of advanced technologies.

\subsection{The Multidisciplinary Engineering Laboratory Course Sequence}

The objectives assessed in this paper is the Multidisciplinary Engineering Laboratory (MEL) sequence, which was replaced three traditional, closed, theory-verification laboratory courses in electrical circuits, fluid mechanics, and stress analysis in $1997^{3}$. As its name implies, MEL's educational objectives are focused on experiments that integrate multiple subjects. MEL goals are to prepare graduates that can integrate multiple disciplines, extend their knowledge to new topics over their professional lifetime, be team and project leaders, and implement 
instrumentation in engineering projects and products. The courses are taught in sequence (MEL I, MEL II, and MEL III) in the sophomore, junior and senior years to facilitate implementing a complex set of educational objectives.

To encourage the development of open-ended problem solving skills, the MEL courses avoid the step-by-step procedures presented in traditional laboratory courses ${ }^{4}$. In a traditional experiment, students are given a series of steps to follow to verify a theory. In these types of courses, students can just go through the motions to get the information necessary to "fill in the blanks" in a laboratory report and not really understand the material. In MEL, students are presented with a simulated industrial problem, provided with a set of reference information and hardware, and expected to design their own experimental procedure. The students review the reference information and the objectives in the laboratory, plan a procedure, and prepare a simple model that is submitted before class. Once in class (see Figure 1), they assemble the apparatus, perform the experiment, modify their procedure, and report their results.

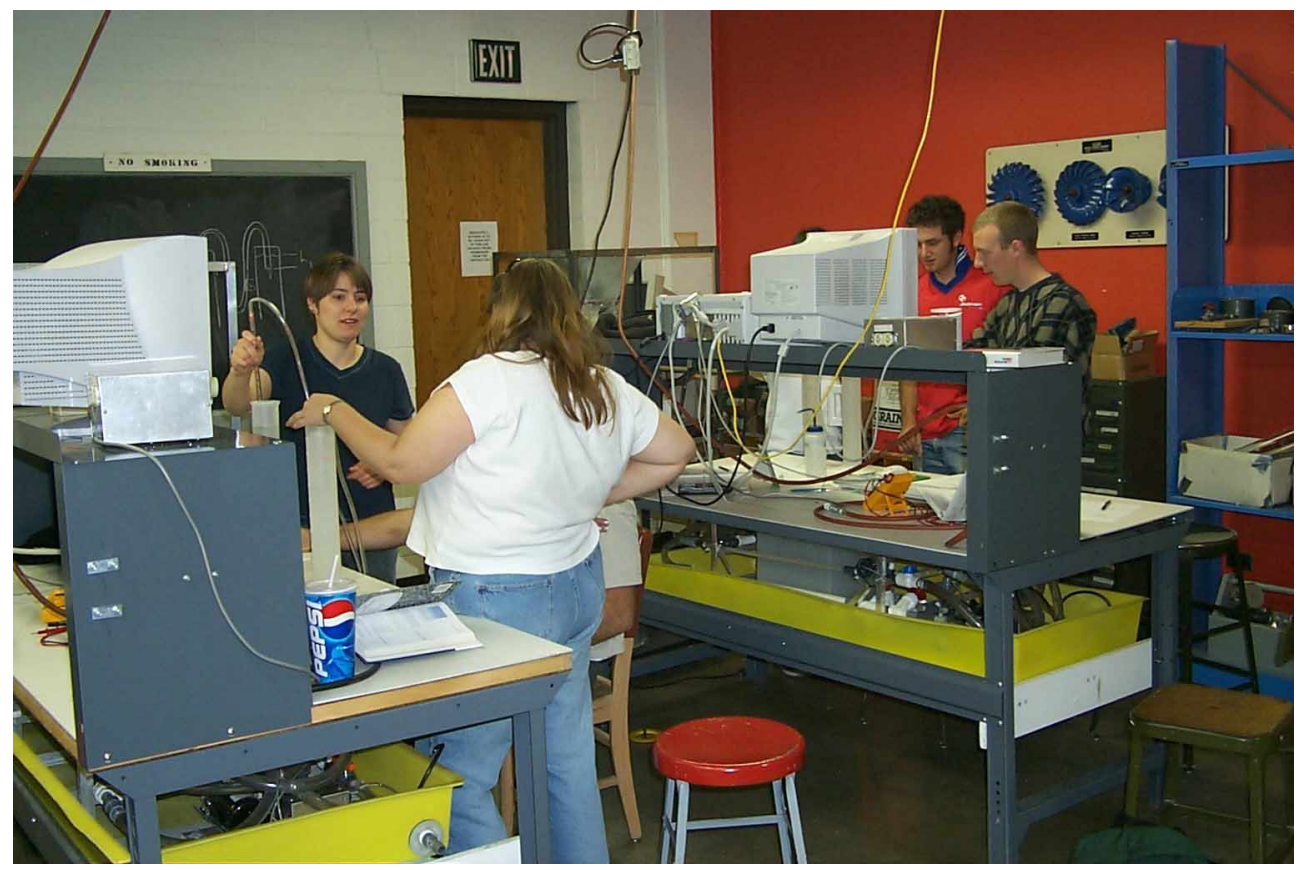

Figure 1. MEL II Students Working an Experiment

\section{The Unique Educational Objectives of the MEL Course Sequence}

The purpose of this paper is to merge data from multiple assessment techniques to evaluate how well we are progressing to meet the educational goals of the MEL course sequence and to guide future actions to meeting the objectives. This section of the paper describes the course objectives. The main focus of most laboratory sequences is subject matter depth. Subject matter competency is one of the MEL educational objectives, but MEL has a longer list of objectives (shown in Table 1) that are developed sequentially. These objectives fit the goals of the broad engineering degree in the CSM Engineering Division, but they are applicable to many other undergraduate engineering programs, especially those desiring ABET accreditation under the new EC2000 criteria 5 . 
Table 1. MEL Educational Objectives.

\begin{tabular}{|ll|}
\hline 1. & Enhance student's thinking maturity. \\
\hline 2. & Encourage students to integrate knowledge from several courses. \\
\hline 3. & Emulate industrial practice by using a systems and applications context. \\
\hline 4. & Build subject matter competency in fundamental engineering topics. \\
\hline 5. & Actively learn the skills of efficient and accurate experimenters. \\
\hline 6. & Improve student retention of laboratory/experimental skills and hardware. \\
\hline 7. & Build life-long learning skills. \\
\hline 8. & Experience a variety of learning styles. \\
\hline 9. & Enhance group and teamwork skills. \\
\hline 10. & Enhance communications skills. \\
\hline
\end{tabular}

\subsection{Implementing the MEL objectives}

Several major challenges were identified and solved during initial implementation of the MEL course sequence. One was teaching a uniform curriculum that meets the above objectives to a large number of students (typical enrollment shown in Table 2) in a division where the overall student/faculty ratio is approximately 30 . The maximum enrollment is 30 students per section in MEL I, and 18 students per section in MEL II and III. The second was developing the facilities to support the MEL sequence in a division that has grown from 150 undergraduates to over 850 over the last 20 years with little increase in physical space. The third problem was writing new experiments with exploratory pedagogy, combining them into three published laboratory manuals, and developing a course web site. The fourth was training instructors and graduate teaching assistants to mentor and coach the educational processes that would lead to fulfilling the objectives. The fifth problem was developing new, inexpensive, reliable experimental equipment to support discovery-based multidisciplinary experiments.

Table 2. MEL Enrollment in the 2000-2001 Academic Year.

\begin{tabular}{|l|r|r|r|r|}
\hline & \multicolumn{2}{|c|}{ Fall 2000 } & \multicolumn{2}{|c|}{ Spring 2001 } \\
\hline Laboratory Course & Sections & Enrollment & Sections & Enrollment \\
\hline EGGN 250 (MEL I) & 5 & 146 & 7 & 174 \\
\hline EGGN 350 (MEL II) & 6 & 65 & 8 & 115 \\
\hline EGGN 450 (MEL III) & 2 & 22 & 3 & 41 \\
\hline Total & 13 & 233 & 18 & 330 \\
\hline
\end{tabular}

MEL teaches problem solving skills by engaging students in the process. Therefore, instructors must balance between a "hands-off approach and a traditional explain-all-the-steps approach. An instructor and a teaching assistant (TA) are present in every MEL section to provide mentoring and coaching support to students who are struggling to discover the operation of instruments and develop experimental procedures on their own. Some universities may not consider this an effective use of instructional resources, and continue to use step-by-step procedures that students can follow with less mentoring. Instructors may be lecturers, adjunct or tenure-track faculty, and often have served in industry. TAs are graduate students in the Engineering Systems program or 
a related department. A major problem is that MEL new to our campus and is significantly different from laboratory courses taught at other universities that our graduate students lack previous experience. Therefore, we provide training for TAs and instructors in coaching to improve thinking maturity. ${ }^{6}$ As TAs become more proficient at coaching in MEL, we will reduce the number of lecturers and adjunct professors. For example, one of the sections of MEL II is being taught solely by a graduate TA; however, this TA is exceptional since he tool the MEL sequence as an undergraduate and has had two semesters experience as a TA working with an instructor. A professor oversees all instructors and TAs in MEL I, II and III.

Before coming to class, students study the experiment requirements, read reference material, and make connections to other course material. They prepare answers to a mandatory preexperiment report that requires them to model the experiment to predict results and develop a preliminary step-by-step procedure that minimizes time to conduct the experiment and minimizes errors. Each MEL class begins with a 15 to 20 minute introduction by the instructor to focus the students on the task at hand and to answer preliminary questions. Lectures do not give step-by-step instruction on operating instrumentation. Students are expected to discover how to operate new instrumentation using reference materials and cooperative learning. Students then form groups of three, with each team working at their own workbench. The team modifies the procedures the members have written individually prior to coming to class. At the end of the experiment, students individually submit their final procedure as part of a report. The experiments, pre-experiment reports, results reports, and reference material for the MEL course sequence are available in the laboratory manuals $7,8,9$ and on the course website by following the links from the CSM website ${ }^{10}$ to the Engineering Division and to the MEL website.

\subsection{Thinking Skills}

The thinking maturity objective is one of the most important and most difficult to implement and assess; therefore we will provide some additional background. The MEL experience is designed to sequentially enhance thinking maturity by helping students develop the abilities to ${ }^{4}$ :

- Reduce complex systems to their component parts.

- Accept ambiguity and identify and develop alternative solutions to a problem.

- Assemble components into a structure not clearly there before.

- Make judgments using criteria and evidence.

- Make commitments based on their own judgments, not an authority's.

It is necessary to enhance thinking sequentially, since students don't mature within one semester. In fact, there are a wide variety of levels of thinking maturity among the students at CSM ${ }^{11}$. To enhance thinking maturity, the experiments are designed so students perform the activities shown in Table 3. The required actions are numerous and we do not expect students in MEL I to complete them all correctly. However, with continual coaching through the sequence of courses, our goal is to make students comfortable and confident with the process even though the complexity of the multidisciplinary experiments increases as students advance through the course sequence. 
Table 3. Thinking Maturity Goals and MEL Experiment Required Actions.

\begin{tabular}{|c|c|}
\hline Goal & Required actions \\
\hline $\begin{array}{l}\text { Reduce complex systems to their } \\
\text { component parts. }\end{array}$ & $\begin{array}{l}\text { Read experiment requirements } \\
\text { Read reference material } \\
\text { Decompose problem } \\
\text { Develop a procedure in pre-laboratory report }\end{array}$ \\
\hline $\begin{array}{l}\text { Accept ambiguity and identify } \\
\text { and develop alternative solutions } \\
\text { to a problem. }\end{array}$ & $\begin{array}{l}\text { Develop alternative procedural steps } \\
\text { Answer pre-experiment questions on reading } \\
\text { Model experiment in pre-laboratory report } \\
\text { Discover how to use instruments. }\end{array}$ \\
\hline $\begin{array}{l}\text { Assemble components into a } \\
\text { structure not clearly there before. }\end{array}$ & Assemble apparatus without instructions \\
\hline $\begin{array}{l}\text { Make judgments using criteria } \\
\text { and evidence }\end{array}$ & $\begin{array}{l}\text { Gather data } \\
\text { Compare data with model } \\
\text { Evaluate and revise procedure } \\
\text { Answer questions in results report }\end{array}$ \\
\hline $\begin{array}{l}\text { Make commitments based on } \\
\text { their own judgments, not an } \\
\text { authority's. }\end{array}$ & $\begin{array}{l}\text { Defend conclusions to team members and } \\
\text { instructors }\end{array}$ \\
\hline
\end{tabular}

To further enhance thinking maturity, the MEL course sequence connects with CSM project courses to develop these abilities. Sharing this educational objective in a mixture of courses emphasizes its importance, provides a more coherent educational experience, and is more effective in raising students' levels of thinking than a non-integrated approach. MEL also helps students make the transition between basic science and math, engineering science, and design.

MEL does not use cliented, open-ended problems as experiments like the design courses, or the problem-based laboratories like the CMU Chemical Engineering Undergraduate Laboratory. ${ }^{12}$ MEL experiments however, are designed to require students to practice the above thinking skills. The experiments are also required for all students, so subject matter competency in multiple areas is provided for everyone and is not project specific. Other laboratory courses require students to decompose a problem, but they do not integrate problem decomposition with the other thinking skills listed above ${ }^{13}$.

\section{Assessment}

\subsection{Independent Evaluator Group Assessment of MEL I}

Because MEL was completely new, we had to develop all of the experiments, three laboratory manuals, a course web site, training materials for the teaching assistants and instructors, the exams, the experimental apparatus including hardware and instrumentation, and modify existing laboratory space which is shared with other courses. Therefore implemented MEL in phases and assessed each phase as we went. We began with MEL I. The initial MEL I pilot class was a small section of our traditional electrical circuits laboratory course that was asked to volunteer. 
After MEL I was underway, we began a pilot course of MEL II and finally initiated MEL III. The pilot courses were taught parallel to the traditional laboratory courses that we replaced. The traditional courses became our control groups. We obtained valuable information from the contrast between control and pilot groups, but that has not been the case at other universities ${ }^{14}$.

The experiments were developed by a group of professors. Then, a group of four senior students who had already completed the traditional laboratories tested the experiments. Finally pilot class completed the experiments, so the experiments were tested three times before they were used in a required course.

We conducted several assessments during the development of the MEL sequence. In this assessment, we are not evaluating MEL faculty for tenure or promotion. Our only objective is to assess how well the MEL course sequence was meeting the educational objectives. King et $\mathrm{al}^{15}$ provides full assessment reports. The following sources were used for assessment data:

- Focus Groups Led by Independent Evaluators

- Independent Evaluator Classroom Observation

- Survey Instrument

- CSM Student Evaluation Forms

- Alumni Survey

- Instructor Observations

- Exam Questions

If our course sequence was focused only one objective we could have use a single test, like a holistic assessment of writing where grades on pre- and post-tests evaluate performance against objectives $^{16}$. We recognize that when only one of the above assessment sets is used, an erroneous or incomplete view of the performance against objectives may result ${ }^{17}$. Therefore we merged the data to develop a more reliable assessment outcome. Other universities have used multiple sources of assessment data. For example, a virtual laboratory at U. of Texas was assessed with questionnaires, observations, interviews, homework grades, and exam scores ${ }^{14}$. However, they did not compare the usefulness of the various assessment data types. Still another technique is to usestudent written responses to a scenario assignment ${ }^{18}$. However, we did not believe this would adequately cover our broad range of objectives.

The independent assessment team of faculty from other departments at CSM (Drs. Pavelich, Chemistry; Olds, Liberal Arts; Pang, International Studies; and Streveler, Student Services) used focus groups, and classroom observations to gather comparative data between MEL and the control group in EGGN 383 (the traditional electrical circuits laboratory). For the focus group assessment, the assessors divided the class into groups of 13 students and asked two general questions: "How would you describe this course" and "What worked well, what didn't?" The discussion was tape recorded so it could be evaluated by other assessors at $t$ later date. The assessors were neutral in their comments during the discussion and kept the conversation going by asking clarifying questions, calling on students who hadn't provide input, and refocusing the discussion. The discussions lasted approximately 20 minutes. 
During the classroom observations, the trained independent observers attended several different MEL and control group class sessions. They took notes on what was going on in general in the classes and in particular what the students were doing. They observed for about 40 minutes in each class. This technique has been replaced or augmented by video interaction analysis at some universities ${ }^{19}$.

They concluded that MEL I definitely met its goals; it caused more and deeper learning, with obvious integration of topics and student excitement about the experience. However, they were concerned that MEL may be at the extreme end of what students can handle. Specific statements heard by the three assessors were:

- MEL is open-ended, EG383 is cookbook,

- MEL forces critical thinking and deeper learning,

- MEL focuses on how to learn, EG383 on what to learn,

- Only MEL integrates circuits, fluids and strengths;

- MEL students have an excitement about the experience that EG383 students do not, MEL is perceived as much more "real-world", MEL students use teamwork in a more sophisticated fashion,

- MEL teaching is more Socratic (coaching, not telling)

- MEL open-endedness requires much more teacher time

- MEL creates a higher frustration level than needed.

- The background supplied at the start of a MEL assignment often seems overwhelming.

- Information may have been incomplete or inaccurate in some MEL assignments.

- Non-Engineering students felt their background was inadequate for MEL and it was inappropriate to their needs.

- There may be too much depth expected or too many assignments for success with less devoted faculty.

All students learned in MEL but many seemed disturbed by their rate of learning being slower than that of others. They lacked confidence that they could do the work on their own.

\subsection{Survey Results}

Dr. Gosink developed and analyzed a written survey ${ }^{15}$. Table 4 summarizes the results of the question on engineering knowledge and skills where $4=$ strongly agree and $0=$ strongly disagree. 
Table 4. Gains in Engineering Knowledge and Skills

\begin{tabular}{|lll|}
\hline Components & Mean Score \\
\hline \multicolumn{1}{|l|}{} & EGGN 383 & MEL \\
\hline $\begin{array}{l}\text { a. This lab requires me to apply knowledge of mathematics, } \\
\text { science or engineering. }\end{array}$ & 2.82 & 3.61 \\
\hline $\begin{array}{l}\text { b. I feel that I can apply what I've learned in this lab to real } \\
\text { world problems. }\end{array}$ & 2.27 & 3.17 \\
$\begin{array}{l}\text { c. My lab class really requires me to think about what I am } \\
\text { doing rather than just plugging numbers into formulas. }\end{array}$ & 2.73 & 3.70 \\
\hline \begin{tabular}{ll} 
d. This lab teaches me to design and conduct experiments. \\
\hline e. This lab teaches me to analyze and interpret data.
\end{tabular} & 2.55 & 3.39 \\
\hline $\begin{array}{l}\text { f. My lab class is preparing me for higher level engineering } \\
\text { courses. }\end{array}$ & 2.18 & 3.43 \\
\hline $\begin{array}{l}\text { g. This lab provides me with the ability to use the techniques, } \\
\text { skills, and modern engineering tools necessary for } \\
\text { engineering practice. }\end{array}$ & 2.55 & 3.13 \\
\hline $\begin{array}{l}\text { h. I feel confident that I could design an experiment to } \\
\text { calibrate a new laboratory or field apparatus or sensor that my } \\
\text { future employer might purchase. }\end{array}$ & 1.55 & 2.78 \\
\hline $\begin{array}{l}\text { i. This lab teaches me to solve engineering problems on my } \\
\text { own. }\end{array}$ & 2.45 & 3.17 \\
\hline
\end{tabular}

\subsection{Independent Evaluator Assessment of MEL II}

Dr. Streveler assessed MEL II after it was implemented Her report ${ }^{15}$ concluded:

1. Students refer to traditional labs as "plug and chug" and to MEL as "open-ended". It was clear that MEL students sometimes wrestled with the fact that open-endedness requires more time and effort on their part.

2. MEL students mentioned that because the lab procedure was not specific that they needed to communicate with their lab partners. Students in traditional labs also communicate with each other, but on a more ad hoc basis.

3. Written communication skills stressed in some traditional labs, but there is not as much opportunity to practice verbal communication skills in traditional labs as there is in MEL labs.

4. MEL students said explicitly that teamwork was more important in MEL than in other labs because one needed to rely on other students to determine the lab procedure.

5. During observation of MEL and traditional labs, MEL students were more consistently engaged in the particular task at hand and with each other. 


\subsection{Student Evaluation Scores}

The students in the course evaluate all courses at the Colorado School of Mines. The students mark a computer scored form in the $13^{\text {th }}$ week of the 16 week semester which is computer scored generating an automatic report to administration, students, departments, and faculty. The students score each question by marking one of five boxes labeled A, B, C, D, or E. A is usually the highest grade, and in the scoring, each $\mathrm{A}$ mark receives $4, \mathrm{~B}=3, \mathrm{C}=2, \mathrm{D}=1$ and $\mathrm{E}=0$. Table 5

shows how scores for MEL compared with the average scores given to CSM courses ( $k$ = below

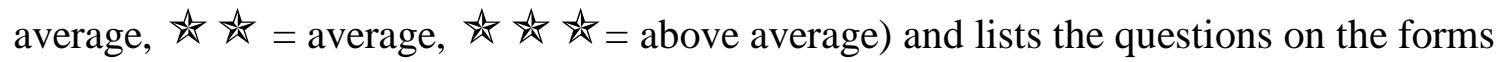
distributed in the MEL courses since Spring Semester 1997. The selection of questions is limited, to a choice among questions on a prescribed list. The questions are divided in three categories depending on the method of selection. The entire CSM faculty and administration agreed on the core questions (Nos. 1- 14) which are on every form. The department head or division director selects a set of questions for all courses in their unit (Nos. 60, 64, 71, 76, 81, 102). The course instructor selects the remaining questions. 
Table 5. Student Evaluation Form Questions used in MEL courses.

\begin{tabular}{|c|c|c|}
\hline Score & No. & Question Text \\
\hline 为谈 & 1 & Course material is well presented. \\
\hline 谈谈 & 2 & Complex material is well explained. \\
\hline 头谈 & 3 & The instructor accessible. \\
\hline 谈谈 & 4 & Assignments are well explained. \\
\hline 头谈 & 5 & How demanding is this instructor \\
\hline 谈谈谈 & 6 & Work required for amount of credit \\
\hline 头谈谈 & 7 & The instructor meets scheduled classes regularly. \\
\hline 虾虾 & 8 & The instructor grades and returns assignments and tests promptly. \\
\hline 弥虾 & 9 & This instructor facilitated your learning. \\
\hline 头弥谈 & 10 & Assignments are relevant \\
\hline 头为访 & 12 & Grading is fair. \\
\hline 头为为 & 13 & The instructor knows the course material. \\
\hline 弥弥 & 14 & Overall rating of instructor: A-Superior, C-Average, E-Poor \\
\hline 虾弥 & 42 & The experiments help to understand the principles of the field. \\
\hline 虾谈 & 43 & The experiments teach ideas which are useful outside the laboratory \\
\hline 谈谈 & 44 & The experiments help learn laboratory techniques and procedures. \\
\hline 隹 & 45 & The procedures for experiments are clearly described. \\
\hline 虾谈 & 46 & The experiments stimulate interest in the subject. \\
\hline 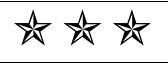 & 47 & How advanced are the experiments \\
\hline 头办 & 48 & Laboratory assistants help the student to clarify problems. \\
\hline 虾 & 49 & A well-written Laboratory Manual is used. \\
\hline 谈谈 & 50 & Laboratories have appropriate equipment. \\
\hline 虾谈 & 51 & Laboratories have up-to-date equipment. \\
\hline 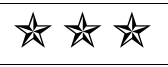 & 60 & The instructor teaches with enthusiasm. \\
\hline 谈谈 & 61 & Instructor ability to clarify and lead students to understand. \\
\hline 虾弥 & 62 & Instructor is able to explain the material in different ways. \\
\hline 谈访 & 64 & Instructors knowledge of current research or work experience. \\
\hline 谈谈 & 66 & The instructor is willing to discuss and help students outside of class. \\
\hline 虾谈 & 68 & The instructor challenges students intellectually. \\
\hline 谈访 & 71 & Rate this course overall A-Excellent, C-Avg, D-Below Avg, E-Poor \\
\hline 头谈 & 73 & The instructor encourages creativity. \\
\hline 虾谈 & 76 & No classroom embarrassment when errors occur. \\
\hline 谈访 & 81 & Demonstrations or examples are used to clarify difficult material. \\
\hline 谈谈 & 102 & The instructor involves the student in thinking and problem solving. \\
\hline
\end{tabular}


The final report to FIPSE ${ }^{15}$, who funded the initial development of MEL, contains a complete analysis of student evaluation scores. The analysis includes calculating a weighted average for each question that is graphed over time.

\subsection{Alumni Assessment}

Independent evaluators conducted a telephone survey of CSM Alumni who completed one or more of the MEL courses ${ }^{15}$. The following summarizes the responses.

To what extent did MEL mirror what you do in your job?

In general, most respondents used the teamwork skills, open-ended problem solving skills, and knowledge of working with multidisciplinary systems. A few used the technologies taught in MEL.

What worked in MEL, what didn't?

Initially the hardware was not reliable and the course was disorganized, but it improved every semester. After a few semesters, the hardware and experiments for implementing the multidisciplinary concepts seemed to work well. But some students may not have been mature enough to thoroughly comprehend the concepts in MEL I. The laboratory computer systems did not always work as well as they should.

What did you see as the strengths and shortcomings of your MEL Lab courses?

The course was more oriented to real-world applications than traditional laboratory courses. However, non-EG majors were not comfortable with the course, and there seemed to be too much work for the number of credit hours.

\subsection{Instructor Observations}

Instructor experience in teaching all courses in the sequence provides a couple of insights not available from the other assessment tools. First, MEL I students typically claim that the laboratory equipment is faulty when in fact they have wired the circuit incorrectly and are not yet adapt at diagnosing errors. The number of faulty equipment claims in MEL III is much less, but when students suggest faulty equipment, they are more often correct. Second, students are more confident in MEL III and they are proud of their ability to solve problems on their own. Consequently, they ask fewer questions, but when they ask one, it is more sophisticated, which makes it more difficult for the instructor to help them quickly.

\section{Merging Objectives and Assessment Results}

Each of the assessment techniques had strong and weak points in relation to each of the objectives. Table 6 identifies the effectiveness of each assessment technique for evaluating the MEL course objectives. 
Table 6. Assessment Technique Effectiveness in Assessing MEL Course Objectives

\begin{tabular}{|c|c|c|c|c|c|c|c|}
\hline \multirow{2}{*}{$\begin{array}{l}\text { Course } \\
\text { Objective }\end{array}$} & \multicolumn{7}{|c|}{ Assessment Method } \\
\hline & $\begin{array}{l}\text { Survey } \\
\text { Inst. }\end{array}$ & Exam & $\begin{array}{l}\text { Classroom } \\
\text { Observation }\end{array}$ & $\begin{array}{l}\text { Focus } \\
\text { Group }\end{array}$ & $\begin{array}{l}\text { Student } \\
\text { Form }\end{array}$ & $\begin{array}{l}\text { Alumni } \\
\text { Survey }\end{array}$ & $\begin{array}{l}\text { Instructor } \\
\text { Obs. }\end{array}$ \\
\hline $\begin{array}{l}\text { Thinking } \\
\text { maturity. }\end{array}$ & 弥 & 访 & 头炎 & 谈谈访 & 头 & 论弥弥 & 头为 \\
\hline $\begin{array}{l}\text { Integrate } \\
\text { knowledge }\end{array}$ & & 头头头 & & 头 & & 虾谈谈 & 头头谈 \\
\hline Applicable & 为 & 谈谈 & & 虾 & is & 虾谈谈 & 头弥谈 \\
\hline $\begin{array}{l}\text { Subject matter } \\
\text { competency }\end{array}$ & 虾 & 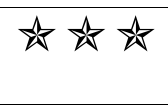 & & 虾 & 头 & 头谈 & 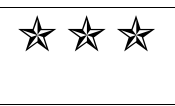 \\
\hline $\begin{array}{l}\text { Experimentation } \\
\text { skills }\end{array}$ & 为 & 为虾虾 & & 谈 & 访 & 头虾 & 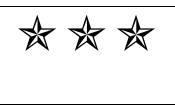 \\
\hline Retention & 必 & 为虾虾 & & 办 & 虾 & 头虾炏 & 必虾烦 \\
\hline $\begin{array}{l}\text { Life-long } \\
\text { learning }\end{array}$ & 谈 & 为 & 为访 & 谈谈谈 & 访 & 弥谈出 & 为为烦 \\
\hline $\begin{array}{l}\text { Learning } \\
\text { styles. }\end{array}$ & 必 & 踏 & 头炎 & 头炇为 & 为 & 头谈谈 & 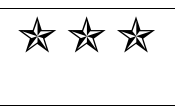 \\
\hline Teamwork & 访 & & 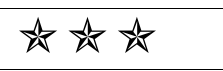 & 虾 & & 为虾虾 & 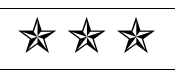 \\
\hline Communications & & & & & & & 谈谈谈 \\
\hline
\end{tabular}

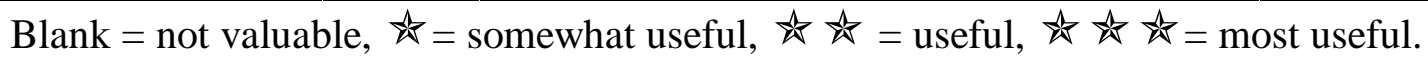

The following discussion explains the results in Table 6 .

4.1 Enhance student's thinking maturity, build life-long learning skills, and experience a variety of learning styles.

Survey Instrument - Table 4 presents some data from the survey instrument that provides positive indicators for impact on thinking maturity. However, it is difficult to phrase written questions on a form to completely assess thinking maturity.

Exam Questions - The final examination for the course is a practical exam where students use laboratory equipment and instruments to answer two types of questions. One question is very similar to an experiment performed during the semester. The second question requires students to apply what they have learned to a new concept. Most students have performed well on the second question.

Independent Evaluator Classroom Observation - The independent evaluator's reported observing activities that will enhance thinking maturity in $\mathrm{MEL}^{15}$. For example, the following activities were reported: 
"One group is having trouble. They are brainstorming and trying things out rather than asking the instructor for the answer. They are using a divide and test approach to identifying the problem."

"Many students are digging into the supply cabinets for what they need. They seem confident."

"Very little reading of instructions. More focused on equipment and talking."

Whereas observations of the control group were that experiments seem simpler that MEL's. There was no sense of neophyte engineers solving a problem, there was much more sense of students going line-by-line through the instructions. The room lacked energy.

Therefore classroom observations by trained, independent observers showed that the activities we believe will lead to more mature thinkers were underway. However, they do not ultimately measure thinking maturity on the Perry Scale ${ }^{11}$.

Focus Groups Led by Independent Evaluators - The trained independent evaluators obtained the comments listed in section 3.1 of this paper during the focus group sessions. The evaluators concluded the students were learning more than in traditional labs, the students were more excited, and they were more confident in their abilities. Like classroom observations, the right activities were occurring, but this technique will not lead to actual Perry Scale measurements.

CSM Student Evaluation Forms - Two questions apply indirectly to thinking maturity: 68, "The instructor challenges students intellectually," and 102, "The instructor involves the student in thinking and problem solving." The scores on question 102 are graphed in Figures 1, 2, and 3. The differences in MEL I, II, and III may be an indicator that thinking is maturing. Scores for question 68 also improve over the sequence, from an average of about 2.7 to 3.5, so not as dramatically as question 102. Furthermore these questions do not address thinking maturity outcomes, just that the professor challenges the students intellectually and involves students in thinking and problem solving. Therefore the information is not as pertinent as the independent observer assessments.

Alumni Survey - The alumni survey provided excellent insight into the actual outcomes of the MEL program. For example, when asked to what extent MEL mirrored what they did in their jobs, most alumni responded with comments like, " The fluid mechanics fundamentals have been helpful in my current position, but the advanced technology hasn't. The experience in openended problem solving has been generally helpful." "In my current position, I just got handed 9000 pages of plans and specifications in an area where I have little background and I have to figure it out. This is just like MEL." These type of comments indicated an improvement in thinking maturity, but it may have been due to other factors and perhaps a combination of factors, not just MEL. On the other hand, one alumnus responded, "I work with pre-stressed concrete and don't use MEL circuits." So we didn't improve the thinking maturity of all graduates. 
Instructor Observations - Instructors observes students asking more sophisticated questions in MEL III than in MEL I indicating a progression in thinking maturity as students progress through the course sequence.

\subsection{Encourage students to integrate knowledge from several courses.}

Survey Instrument - Our questions did not address this issue, but questions could be modified.

Exam Questions - Since our final exam simulates the multidisciplinary experiments done in the laboratory, this assessment technique assesses students ability to integrate knowledge.

Independent Evaluator Classroom Observation - It was difficult for some of our evaluators who were not from engineering disciplines to determine integration.

Focus Groups Led by Independent Evaluators -Focus group discussions brought out the integration of subject matter via student comments like, "MEL integrated fluids, circuits, and strengths while the control classes only studied circuits."

CSM Student Evaluation Forms - None of the standard questions available for student evaluation forms cover integration of material.

Alumni Survey - The alumni survey provided information on the importance of multiple discipline integration with comments like, "As a CE, MEL gave a good multidisciplinary background for working with electrical and mechanical engineers."

Instructor Observations - Instructors notice the growing ability of students to experiment with increasingly sophisticated multidisciplinary systems as they progress through the MEL sequence.

\subsection{Emulate industrial practice by using a systems and applications context.}

Survey Instrument - Table 4 shows a significantly higher score for MEL on students attitude about applying the course to real world problems.

Exam Questions - Our questions emulate industrial practice, so students ability is evaluated on the exams.

Independent Evaluator Classroom Observation - The assessors had little engineering industrial experience so they were not able to evaluate this objective.

Focus Groups Led by Independent Evaluators - The focus groups reported that students perceive MEL as being more real world that the control course.

CSM Student Evaluation Forms - Question 43, “The experiments teach ideas that are useful outside the laboratory" indirectly provide information on industrial practice emulation. 
Alumni Survey - The alumni survey is the best assessment tool for this objective. Most alumni were positive about the applicability of the MEL program with comments like: "MEL is more real world because the problems are more open-ended rather than formula bound."

"The open-ended projects are just like industry. You have to use creativity."

Instructor Observations - Many of our instructors are adjunct professors who leave their jobs in industry and at government laboratories to teach a section of the MEL program for a few hours. They are impressed with MEL's applicability and they offer suggestions for improvement that makes MEL even more applicable.

\subsection{Build subject matter competency in fundamental engineering topics.}

Survey Instrument - Several of the questions in Table 4 address this issue and students rated MEL higher than the control class.

Exam Questions - The exam questions require knowledge of fundamental engineering topics.

Independent Evaluator Classroom Observation - Because the evaluators were not engineering professors, they were not able to rate this objective.

Focus Groups Led by Independent Evaluators - Students perceived that MEL forces critical thinking and deeper learning.

CSM Student Evaluation Forms - Student evaluation form question 42, "The experiments help to understand the principles of the field" provides student perceptions on this issue.

Alumni Survey - A few alumni addressed this issue with comments like: "The fluid mechanics fundamentals have been helpful in my current position." "I was pleased with the computer data acquisition which I use in my job."

Instructor Observations - Instructors observe students becoming more proficient with fundamental engineering topics as students progress through the MEL sequence.

4.5 Actively learn the skills of efficient and accurate experimenters, and improve student retention of laboratory/experimental skills and hardware.

Survey Instrument - One of the questions shows students perceived they were learning to design and conduct experiments better in MEL than in the control courses.

Exam Questions - The practical nature of the final exam requires students to show proficiency in experimentation.

Independent Evaluator Classroom Observation - Assessors observed students discovering how to use instruments without following instructions, but the assessors did not have the background to judge student competency. 
Focus Groups Led by Independent Evaluators - The focus groups provided student perceptions that they were learning experimental skills.

CSM Student Evaluation Forms - Student perceptions are scored in question 44. "The experiments help students learn laboratory techniques and procedures."

Alumni Survey - Some alumni are using experimental processes in their jobs and they reported comments like: "Testing, sensors, reading data, knowing what to look for from MEL all used in current job."

Instructor Observations - Instructors observe student proficiency with experimental skills increasing throughout the MEL sequence.

\subsection{Enhance group and teamwork skills.}

Survey Instrument - None of the questions acquired data about student perceptions of teamwork skills enhancement.

Exam Questions - The final exam is an individual exam. It does not measure teamwork skills. So we hand out a form to every student where they rate their own performance on the team as well as their team members performance. The results of this form are used to calculate a significant portion of the final grade.

Independent Evaluator Classroom Observation - This assessment method was extremely useful in assessing teamwork skills. The assessor commented: "MEL students use teamwork in a more sophisticated fashion."

Focus Groups Led by Independent Evaluators - The focus groups provided some information on students perceptions of their teams like: "Team members worked on separate pieces then they integrate it all." "Our super leader took charge and took us through the stuff, we would have been lost without him."

CSM Student Evaluation Forms - No questions assess student perception of teamwork skills.

Alumni Survey - Several alumni reported on the value of the teamwork practice they received in MEL with comments like: "MEL gave a great background in teamwork that has been helpful in my current job working with architects, structural engineers, mechanical engineers." "The teamwork aspect was the most applicable (part of MEL to my current job)."

Instructor Observations - Instructors notice that students make their teams work in order to complete the MEL experiments on time. There are fewer team problems in MEL III than in MEL I. 


\subsection{Enhance communications skills.}

With the exception of the instructor's observations from grading written communications, none of our assessment methods to date adequately assessed communication skills. We are planning to implement communications assessments during the coming semester.

\section{Conclusion}

It was not possible to select a single assessment method to evaluate all of the course objectives. Each of the assessment techniques had strong and weak points in relation to each of the objectives. For example, the alumni survey was especially beneficial in helping to gage how well MEL affected thinking skills, and how well MEL emulated industrial practice, while exams helped gage subject-matter competency. The survey form and focus groups provided information on student perceptions that are useful information, but are not actual measures of outcomes. Our independent assessment group was very competent in the pedagogies of thinking maturity and teamwork, but they were not engineers so they were unable to assess the objectives related to subject matter competency.

The assessment results were generally, but not completely favorable and there is still much work to be done to continuously improve MEL. However, the assessment results had a major impact as MEL has become a major focus of the undergraduate program in engineering at CSM. It became the focus of a recent program of excellence award from the Colorado Commission of Higher Education and MEL received an award from the American Council on Education for enhancing educational quality while controlling cost.. Furthermore, CSM has allocated a sizeable piece of a new building, the Center for Technology and Learning Media, to the MEL program, and a proposal to build an addition to the current Engineering Division building (George R. Brown Hall) is being presented to the State, also based on MEL pedagogy and accomplishment. Assessment, especially by independent evaluators, was more influential that instructor or student comments in these initiatives.

\section{Acknowledgments}

Financial support for course development was provided by FIPSE (Fund for the Improvement of Post Secondary Education, U.S. Department of Education). CSM and the Parsons Foundation provided funds for the MEL I experimental apparatus and laboratory modification. NSF ILI Program Grant DUE-9850556, Chevron, and Kennecott provided partial funding for MEL II and III experimental apparatus and laboratory modifications necessary to develop the multidisciplinary sequence. NSF Grant DUE-9653726 provided conference travel funds.

Dr. Nigel Middleton wrote the original FIPSE proposal with Dr. Parker, Gosink, and Glazer. Dr. Terry Parker developed the initial experiments for MEL I and II. Dr. Tom Grover developed much of the experimental equipment for the MEL sequence. Drs Gosink, Pavelich, Olds, Pang, and Streveler conducted assessment activities. 
References:

${ }^{1}$ URL: http://www.usnews.com/usnews/edu/college/rankings/

${ }^{2}$ Gourman, J., “Gourman Report of Undergraduate Programs, 10th Edition, Princeton Review, December 1997.

${ }^{3}$ King, R. H., Parker, T. E., Grover, T. P., Gosink, J. P. \& Middleton, N. T. (1999). A multidisciplinary engineering laboratory course, Journal of Engineering Education, 88 (July), 311-316

${ }^{4}$ King, R. and Streveler R., "Enhancing Student Levels Of Thinking With Laboratory Experiments," Session 2530, 1999 ASEE Annual Conference and Exposition, June 20-23, Charlotte NC.

${ }^{5}$ URL: $\underline{\text { http://abet.org }}$

6 Streveler, R. A. and King, R. H., "Training Engineering TAs to Facilitate Open-Ended Problem Solving," Journal of Graduate Teaching Assistant Development, v 7, n3, 2000, p 139-146.

${ }^{7}$ King, R., Parker, T., and Grover, T., Multidisciplinary Engineering Laboratory I Experiments, CSM Bookstore, August, 2000.

${ }^{8}$ King, R., Parker, T., and Grover, T., Multidisciplinary Engineering Laboratory II Experiments, CSM Bookstore, December, 2000.

${ }^{9}$ King, R., Parker, T., and Grover, T., Multidisciplinary Engineering Laboratory III Experiments, CSM Bookstore, December, 2000.

${ }^{10}$ URL: http://www.mines.edu

${ }^{11}$ Pavelich, M. J. and Moore, W. S., "Measuring the Effect of Experiential Education Using the Perry Model," Engineering Education, v. 85, n. 4, Oct, 1996, pp. 287-292.

12 Cline, M. and Powers, G. J., “Problem Based Learning via Open Ended Projects in Carnegie Mellon University’s Chemical Engineering Undergraduate Laboratory," Proceedings - Frontiers in Education Conference, 1997, p.350354.

${ }^{13}$ Neumann, W. T., Woodfill, M. C., "Leveraging student experience with an integrated instructional laboratory," Proceedings - Frontiers in Education Conference, v3, 1997, p 1239-1242.

${ }^{14}$ Yarbrough, S. E. and Gilbert, R. B., "Development, Implementation, and Preliminary Assessment of Virtual Laboratory," Journal of Professional Issues in Engineering Education and Practice, v 125, n 4, Oct, 1999 , p 147 151.

${ }^{15}$ King, R., T. Parker, J. Gosink, “A Multifaceted Engineering Systems Laboratory,” FIPSE Annual Report, Dept. of Education, 1997.

${ }^{16}$ Larson, D. et al, "A Holistic Assessment of Writing in Design," Proceedings - Frontiers in Education Conference, v 1, Section T2H, 1998, p 231-235.

${ }^{17}$ Olds, B. M. and Miller, R. L., “Assessing a Course or Project,” How Do You Measure Success, ASEE, 1998, p35 -43 .

Proceedings of the 2001 American Society for Engineering Education Annual Conference \& Exposition Copyright (C) 2001, American Society for Engineering Education 
${ }^{18}$ McMartin, F., McKenna, A. and Youssefi, K. "Establishing the Trustworthiness of Scenario Assignments as Assessment Tools for Undergraduate Engineering Education," Proceedings - Frontiers in Education Conference, v3, 1999, p 13c1-7 - 13c1-13.

${ }^{19}$ Regan, M. and Sheppard, S. "Interactive Multimedia Courseware and the Hands-on Learning Experience: An Assessment Study," Journal of Enineering Education, v 85, n 2, April, 1996, p $123-131$.

\section{ROBERT H. KING}

Dr. Robert H. King is a Professor and the Acting Director in the Engineering Division at CSM. Recent research has been in the area of engineering education, developing the MEL sequence. Previous work includes hazardous environment tele-robotics simulation, and computer monitoring systems. He has a B. S. from the U Utah and M.S. and $\mathrm{PhD}$ from Penn State. 